\title{
A Study of the Website Performance of Travel Agencies Based on the EMICA Model
}

\author{
Derong LIN $^{1}$, Zongqing ZHOU ${ }^{2}$, Xiaolin GUO ${ }^{3}$ \\ ${ }^{1}$ School of Management, Xiamen University, Xiamen, China; ${ }^{2}$ College of Hospitality and Tourism Management, Niagara University, \\ New York, USA; ${ }^{3}$ School of Management, Xiamen University, Xiamen, China. \\ Email: drlin65@xmu.edu.cn, zhou@niagara.edu, xiaolinxmu@163.com
}

Received February $9^{\text {th }}, 2009$; revised April $8^{\text {th }}, 2009$; accepted May $11^{\text {th }}, 2009$.

\begin{abstract}
Recent developments in information technologies (ITs), in particular the popularity of the Internet in the early 1990s, have changed the way that tourism businesses communicate with its customers and the way that promotion and sales of tourism products are conducted. Travel agencies with established websites are in a position to undertake productive marketing activities. This paper uses the extended Model of Internet Commerce Adoption (eMICA) to evaluate the website performance of travel agencies in China, with some modifications of the model for the purpose of the study. The results showed that travel agencies in China were not utilizing the Internet to its full potential, particularly in terms of marketing using its websites. Suggestions and recommendations are also provided based on the findings of this research.
\end{abstract}

Keywords: travel agencies, eMICA model, tourism, China

\section{Introduction}

In recent years, rapid advancements in information technology, particularly the Internet, have created enormous opportunities for traditional travel agencies to target their tourism offerings to a wider market. In response to the increasing demand for tourism information by the travelers, many travel agencies have established websites to promote their services and products. These websites plays an important role in mediating between customers and companies as a channel for information acquisition and business transactions [1].

In the beginning, travel agency websites were simply used as an 'online brochure', in other words, providing static in-formation for the online consumers to view. Today some travel agency websites are starting to find other uses of their websites, such as providing interactive functions and personalizing and customizing its contents based on the characteristics of their target markets. Travel agencies have come to realize that their websites serve as a 24/7 extended office to their customers and represent the quality of their products and services as well as their reputation [2].

Studies on tourism website performance in the developed world have evolved over the years and are not hard to find in the literature, but few can be found regarding developing countries such as China. The purpose of this paper is to introduce an approach for benchmarking the relative maturity of websites used by travel agencies in China, which is generally considered to be a developing country. The approach involves applying an Internet commerce adoption metric, the extended Model of Internet Commerce Adoption (eMICA) developed by Burgess and Cooper [3]. The eMICA model was used to evaluate the extent of tourism website development [4]. The findings of the study contribute to a better understanding of the functionality used in travel agency websites and confirm in general the usefulness of the eMICA model for evaluating websites by tourism businesses such as travel agencies, with suggestions for improving the eMICA model in future research. In addition, this research provides recommendations for industry professionals on how to build well-constructed and effective websites for marketing.

\section{Literature Review}

Studies on the role and impact of the Internet have been conducted in recent years, particularly in the area of advertising and marketing. The Internet has proven to be an effective means of advertising, marketing, distributing 
goods, and information services. Zhou [2] has asserted that for the advertising industry, the Web is both the biggest challenge and the biggest opportunity in a long time. Furthermore, the travel and tourism industry is a very fragmented and an information-rich business, which makes it especially receptive for the benefits that the Internet offers. One of the characteristics of tourism products is that it is intangible, in other words, they cannot be sampled before the purchase decision is made [2]. The information-based nature of the tourism products means that the Internet, which offers global reach and multimedia capability, is an ideal communication vehicle for promoting and distributing tourism products and services [4].

How the Internet changed traditional tourism industry in developed countries has been studied [2]. Burgess et al. [3] explored the level of uptake of the web as a marketing tool by businesses in the regional tourism industry sector in Australia. The Chinese tourism industry has developed its online services and obtained some initial experience. China, as a developing country, has a different tourism Ecommerce development environment in which barriers and challenges are abound and are indicative of a developing country. However, there are only a few researches into the classification and evaluation of tourism websites in China, although in the case of general website assessment, some publications of results do exist but they do not specifically address tourism websites in developing countries.

Many researchers have used content analysis to evaluate the websites of related industries [6]. Murphy et al. [7] used five search engines to search hotel websites in Florida and identified 32 different features from 36 hotel websites that provided on-line reservations. The 32 features were divided into four categories: promotion and marketing, service and information, interactivity and technology and management. Countryman [8] used content analysis to evaluate the official tourism websites of all 50 states in the United States. Tony Chung [9] presented an information quality evaluation model for measuring the performance of hotel websites. The model was developed on the basis of a conceptual framework which consisted of five major hotel website dimensions, including facilities information, customer contact information, reservations information, surrounding area information, and management of websites. Baloglu and Pekcan [10] utilized content analysis to analyze the web-sites of a select group (4-star and 5-star) of hotels in Turkey in terms of site design characteristics (interactivity, navigation, and functionality) and site marketing practices on the Internet.
In relation to the above, Doolin and Cooper [4] has described that commercial website development typically begins simply and evolves over time with the addition more functionality and complexity as firms gain experience with Internet technologies. The extended model of Internet Commerce Adoption (eMICA) model developed by Burgess and Cooper [3] was based on this concept. They used the eMICA model to evaluate the level of website development in New Zealand's Regional Tourism Organizations and highlighted the utility of using interactivity to measure the relative maturity of tourism websites. Since then, the eMICA model has been used frequently. Larson \& Ankomah [5] employed it to evaluate the degree of sophistication of the websites of 20 US states/territories' tourism organizations. Wu and Zhou [11] have also used the eMICA model to study the electronic commerce application level of Chinese tour enterprises.

\section{Methodology}

\subsection{Sampling Procedure}

For the purpose of this study, the travel agencies guide (list) published in 2006 on official tourism bureau web-site (http://www.cnta.gov.cn/) were used as the sampling frame. The guide contains the top 100 travel agencies in China, with different level of operational capabilities. Some travel agencies can only operate within China while others are registered for both domestic and international travel. Out of the 100 travel agencies, we select a total sample of 30 agencies, half of which can run its tour operation within China, while the other half can handle both domestic and international travel.

\subsection{Data Collection}

Search engines, Baidu and Google, were used to find the corresponding websites. As the site performance may be influenced by the type of browser, computer speed, Internet speed, and time of a day, these external factors were controlled when conducting the content analyses of the sites, i.e. same browser, Pentium 4 computer, highspeed Internet connection, and time slot of the day.

\subsection{Instrument}

This study uses the eMICA model developed by Burgess and Cooper to evaluate the hotel websites. The eMICA model consists of three stages, incorporating three levels of business process - Web-based promotion, provision of information and services, and transaction processing. The stages of development provide a roadmap that indi- 
Table 1. The extended model of internet commerce adoption (eMICA)

\begin{tabular}{|c|c|}
\hline EMICA & Examples of functionality \\
\hline $\begin{array}{l}\text { Stage 1-promotion } \\
\text { Layer 1-basic information } \\
\text { Layer 2-rich information }\end{array}$ & $\begin{array}{l}\text { Company name, physical address and contact details, area of business } \\
\text { Annual report, email contact, information on company activities }\end{array}$ \\
\hline $\begin{array}{l}\text { Stage } 2 \text {-provision } \\
\text { Layer } 1 \text {-low interactivity } \\
\text { Layer } 2 \text {-medium interactiv- } \\
\text { ity } \\
\text { Layer } 3 \text { - -high interactivity }\end{array}$ & $\begin{array}{l}\text { Basic product catalogue, hyperlinks to further information, online enquiry form } \\
\text { Higher-level product catalogues, customer support (e.g., FAQs, sitemaps), indus- } \\
\text { try-specific value added features } \\
\text { Chat room, discussion forum, multimedia, newsletters or updates by email }\end{array}$ \\
\hline
\end{tabular}

Stage 3-processing

Secure online transactions, order status and tracking, interaction with corporate servers

cates where a business or industry sector is in its development of Internet commerce applications. In order to accommodate the wide range of Internet commerce development evidenced in industries such as tourism, eMICA incorporates a number of additional layers of complexity, ranging from very simple to highly sophisticated, within the identified main stages of the model. The eMICA model is shown in Table 1.

Promotion is the initial stage of web development, with static information which serves mainly to promote and publicize the business offerings. A second level is also presented where a richer variety of information is available on the web. In other words, this is an additional channel of marketing strategies, offering the company's information online. The second stage described what the eMICA model is when the company website moves to a dynamic information system with a web front end. Within this stage, three levels are identified. Low level of interactivity is characterized by on-line catalogues, links to detailed information and on-line registration form. Medium level of interactivity is characterized with more complete product catalogues, on-line help for users and personalization as well as wider links to industry sites. High level of interactivity is completed by the sites that include chat rooms, discussion forums, multimedia applications and dynamic newscasts.

The third stage identified in the eMICA model is where the web site has a functional maturity which permits on-line transactions. This requires a higher level of security than the previous stages as well as user identification. At this stage users will be able to purchase products and services across the web, maintain an individual profile and obtain personal profiles matching offerings to the individual needs. This is the broadest and most complex ecommerce application since it enables the company to process multiple tasks such as online sales, online orders, online delivery (especially for digital products) and online payment. Thus, in this layer, the company creates an integrated function.
This paper uses the eMICA model to study the travel agency website of China, because the model has been tested and used on tourism industry, and several surveys have been done for the Australian, New Zealand, and Asia-Pacific regional tourism organizations. In fact, there are quite a lot of differences between travel agency web-sites and regional tourism organizations (RTO) websites. In this study, we change and modify the original model created by Burgess and Cooper (2000). In evaluating the travel agency websites, some elements are omitted, but some new ones are added. Similar to the original model, the adopted one from us has three stages, but some of the elements are changed:

\section{Promotion stage:}

1). Contact detail

2). Images

3). Description for the travel agency

\section{Provision stage:}

4). Systematic links to further information

5). Product catalogs (tour routes, accommodation, dining, shopping)

6). Multiple value-added features (key facts, maps, location, news, photo gallery, promotion)

7). Interactive value-added features (currency coverters, interactive maps, downloadable materials, special offers, member's privileges, guest books)

8). Online customer support (FAQs, site map, sitesearch engine)

9). Searchable databases for tour routes under different inquiry condition

10). Online bookings

11). Advanced value-added features (Order form inquiry multi-language support, member lands, multimedia, chat rooms and discussion forums)

\section{Processing stage:}

12). Secure online payment 


\section{3). Services after payment}

This modification brings a clearer and more understandable way for analyzing the study. The stages are separate according to the communication channels that they implement. Information stage only has the elements for B2C communication channel where the travel agencies publish information about their contact detail, area of business, information on company activities etc. Interaction stage contains elements for B2C, C2B and C2C communications, and makes possible two-way interaction with the customers. Transaction stage is the most advanced stage according the model and allows customers to purchase and pay the hotel products online. Furthermore, in this stage, a series of services should follow up after the payment.

\section{Results}

Each travel agency site was assigned an appropriate stage and layer in the eMICA model based on the level of development of the site. A site needed to display functionality up to at least Level 4 to be classified as Stage 2 of eMICA. Sites reaching Level 7 functionality were classified as Stage 2, Layer 2, and those reaching Level 10 functionality were classified as Stage 2, Layer 3.To be classified as Stage 3 of eMICA, a site required functionality at Level 12. The results of the study are shown in Table 2 From the statistical result, only two travel agencies are in the first stage; the majority of examined travel agencies are placed to second stage of the eMICA model; they have inherited the core function and characteristic from first stage, such as contact details, company introduction and images. As the under discussion demonstrates, the prominent difference manifests in the three standard levels of second stage. In the highest stage of the model, none has offered secure online payment, does not need to mention services after payment.

The main difference among these travel agency web-

Table 2. Results of the travel agency websites evaluated

\begin{tabular}{lcc}
\hline Stage of eMICA & Number of sites & $\begin{array}{c}\text { Percentage } \\
\text { of total sites }\end{array}$ \\
\hline Stage 1-Layer 1 & 0 & 0 \\
Stage 1-Layer 2 & 2 & $6.7 \%$ \\
Stage 2-Layer 1 & 7 & $23.3 \%$ \\
Stage 2-Layer 2 & 15 & $50 \%$ \\
Stage 2-Layer 3 & 6 & $20 \%$ \\
Stage 3 & 0 & 0 \\
Total & 30 & $100 \%$ \\
\hline
\end{tabular}

sites is in Stage 2 (Provision). The travel agencies located in the first layer of this stage have acquired systematic links to further, which enable customers to obtain corresponding information conveniently and quickly both inside and outside the websites. Certainly, considerable amount of websites do not have the overall systematic links; when entering the next surface, the information often has the vacancy or is insufficient. In the second layer, the majority of travel agencies have interactive value-added features and site search engine. None of the travel agencies have attributes of the Processing stage, Stage 3 of the eMICA model. In other words, none of the websites have developed to that stage. This may indicate that many people are reluctant to make credit card transactions online for some scruple, especially secure payment.

\section{Discussion}

As the number of websites continues to grow at an explosive rate, how the websites of each industry attract customers will become increasingly critical for business survival. So are in travel agencies. According to this research, the insufficiency of travel agencies in China is in the below aspects:

1) The websites often take oneself as central, but neglect consumer's demand. The content of the websites is not well designed. Generally, when planning the websites, a mentality that we should prominently propagandize the hotel continues. The pages are filled with massive duties manifesto and the enterprise history, but are lack of information or online service which customer really expect to get. Hence, when designing the websites, some critical details should be considered by the professionals of the travel agencies, such as what the customers need and how we can attract them to our sites.

2) Some travel agencies have used Flash video as their front-page, which is not a good choice. The Flash cannot play the role for shedding the light of frontages, but causes them look like rather mediocre, for nearly all of them used the same style. Besides, the Flash has slowed down the visit speed, has disturbed the search engine to stand capturing, and also has affected the customer visitor's friendliness. On the one hand, the search engine cannot be able to distinguish Flash, correspondingly, except the name, nothing can be found by the search engine. On the other hand, taking Flash as the front-page also increased nonessential clicking times before the customers could find the effective information. As an investigation has shown, every time increases time clicks, the visitor can reduce above 30\%. Regarding the foreign visitor, such design is especially unfriendly. 
3) Like any type of information system, the key factor for developing a successful online application is to correctly define user requirements. Some websites are not satisfactory due to ill-defined requirements that do not meet the expectations of users. User evaluation for 'information content' ensures that the information provided on the web is useful, up-to-date, and can meet customer needs and link relevant sites to users. In response to the question 'what are the main purposes to visit hotel websites?', 'to get information' obtained the highest rating. For the question 'what is the most popular online service on travel agency websites?', 'providing information' has listed first. Therefore, as obtaining information is still the main aim of web users, improving the quality and level of web information presentation and management are major tasks for current travel agency website development.

Furthermore, services after payment should be followed, which can be considered to be Layer 2 of the Stage 3. This layer which includes following services is not presented in eMICA model, but it is important and significant from our point of view. Along with guests' individual service demand increasing, the travel agency which can provide order form tracking, accumulation preferential benefit, and regular promotion transmission to guests inevitably occupies superiority in the marketing while competing with others.

\section{REFERENCES}

[1] M. Jeong and C. Lambert, "Measuring the information quality on lodging websites," International Journal of Hospitality Information Technology, Vol. 1, No. 1, pp. 63-75, 1999.

[2] Z. Zhou, "Ecommerce and information technology in hospitality and tourism management," Delmar, 2004.

[3] L. Burgess and J. Cooper, "Extending the viability of
MICA (model of internet commerce adoption) as a metric for explaining the process of business adoption of internet commerce," Paper Presented at the International Conference on Telecommunications and Electronic Commerce, Dallas, November 2000.

[4] B. Doolin, L. Burgess, and J. Cooper, "Evaluating the use of the web for tourism marketing: A case study from New Zealand,” Tourism Management, Vol. 23, No. 5, pp. 557 -561, 2002.

[5] T. Larson and P. Ankomah, "Evaluating tourism web site complexity: The case of international tourism in the U.S.,” Services Marketing Quarterly, 26 (2), 23-37. 2004

[6] H. Bell and N. K. H. Tang, "The effectiveness of commercial internet web sites: A user's perspective,” Internet Research: Electronic Networking Applications and Policy, Vol. 8, No. 3, pp. 219-228, 1998.

[7] Murphy, et al., "Hotel management and marketing on the internet," The Cornell Hotel and Restaurant Administration Quarterly, Vol. 37, No. 3, pp. 70-82, 1996.

[8] C. C. Countryman, "Content analysis of state tourism websites and the application of marketing concept," Proceedings of the Fourth Annual Conference on Graduate Education/Graduate Student Research in Hospitality \& Tourism, Las Vegas, USA, Nevember 1999.

[9] T. Chung and R. Law, "Developing a performance indicator for hotel websites,” Hospitality Management, Vol. 22, No. 1, pp. 119-125, 2003.

[10] S. Baloglu and Y. A. Pekcan, "The website design and internet site marketing practices of upscale and luxury hotels in Turkey,” Tourism Management, Vol. 27, No. 1, pp. 171-176, 2006.

[11] S. Wu and Y. Y. Zhou, "A study of the electronic commerce application level of Chinese tour enterprises based on the eMICA model," The Fifth International Conference On E-Business, 2006. 